\title{
Evaluating Rent Dissipation in the Spanish Football Industry"
}

\author{
Guido Ascari \\ Dip. di Economia Politica e Metodi Quantitativi \\ Via S. Felice 5 \\ 27100 Pavia, Italy \\ Tel: (+39) 0382506211 \\ Fax: (+39) 0382304226 \\ gascari@eco.unipv.it
}

\author{
Philippe Gagnepain \\ Departamento de Economia \\ Universidad Carlos III de Madrid \\ C/ Madrid, 126; 28903 Getafe, Spain \\ Tel: (+34) 916245732 \\ Fax: (+34) 916249875 \\ philippe@eco.uc3m.es
}

\footnotetext{
*Marca is gratefully acknowledged for providing the data. Ascari thanks the Department of Economics at University Carlos III Madrid for the hospitality while starting the research on this paper. The authors wish to thank an Editor as well as two anonymous referees for helpful comments. This paper also benefited from various discussions with Stefan Szymanski as well as participants of the Industrial organization workshop of Carlos III and at the EARIE 2003 conference in Helsinki. All errors are ours. Financial help from Ministerio de Educación y Ciencia, project numbers BEC2001-1653 and SEC2001-1212, is greatfully acknowledged.
} 


\begin{abstract}
This paper proposes to evaluate empirically the consequences of the rent-seeking behavior of football clubs on their costs. The empirical work entails estimating a football wage, result, and demand system with data on clubs competing in the first and second Spanish leagues over the 1996-2003 seasons. The estimation sheds light on wage distortions above a theoretical frontier that differ from $45 \%$ to $52 \%$ over the period considered. This provides an interesting illustration of the financial difficulties faced recently by many European football clubs.
\end{abstract}

\title{
Keywords
}

Football industry, wage distortion, frontier, football demand. 


\section{Introduction}

The recent theoretical literature on sport economics has proposed to consider sporting contests through the window of the tournament and contest theory (Szymanski, 2002). In such framework, sport clubs compete for a financial/non-financial prize. To win the prize, they spend costly effort and dissipate part of the rent that can be obtained from that prize, damaging thus their own profitability. Some features restrain the amount of rent-seeking expenditures, while some others are likely to boost it. ${ }^{1}$ The literature deals mainly with one issue at the time and it is not clear-cut how they interrelate (Szymanski and Valletti, 2003). There seems however to be a consensus on the fact that the competitive interaction impinging on the activity of the contestants may create a financial distortion on their budgets with no relative improvement in performance. Our objective in this paper is to focus on clubs competing in the Spanish football industry and provide an empirical evaluation of these rent seeking expenditures as well as the financial distortion above a theoretical frontier supported by these clubs. Our motivation regarding the choice of the football industry is twofold:

First, the football industry is an interesting candidate to consider if one is willing to deal with the theory of contests. Football leagues are nation wide contests where several clubs compete against each other over a certain period. Clubs spend costly effort to enroll the best players and increase their probability to reach a particular result. Since they are production units of different size and they face different types of audience, it is well accepted that these clubs have asymmetric valuations of the price they run after. Moreover, a football league may offer different prizes, i.e., the best ones compete to win the league while others seek the qualification to the European cup or the weakest try to avoid relegation to second league (see Rosen and Sanderson, 2001 for more details). Different financial stakes that are worth taking into account characterize all these different results. Finally, the recent explosion of clubs expenditures following the advent of the pay-TV has certainly an impact on the value of the different national leagues. The most profligate leagues will be featuring the highest number of international star players and will have the highest value on the international market.

Second, experience has shown that the European football industry is going through one of the most important crisis of its history. Its clubs are very often forced to reduce their budget significantly, or 
some of them go bankrupt. ${ }^{2}$ Examples illustrating this general tendency are numerous: in Spain, clubs spent only 92.3 Millions Euros to enroll new players in the national championship in 2002, which represents a cut of 211 Millions Euros (358 Millions respectively) with respect to what had been invested the year before (two years before respectively). In Italy, three of the most famous clubs of the championship faced important financial difficulties. Two of them, Roma and Lazio, found it difficult to reduce their deficit and to meet the requirements to be allowed to register in the championship, while a third one, Fiorentina, went bankrupt. In addition, several players of the other teams accepted to reduce their earnings and some club directors advocated some corrective measures. ${ }^{3}$ In England, several clubs competing in the second league went close to bankruptcy (Bradford and Leicester among others). In Germany in 2002, the clubs invested 102.2 Millions Euros in hiring, which represents a $35 \%$ cut with respect to the previous year. The total amount of debt in 2003 in the Spanish and Italian Leagues amounts to 1.625 and 1.800 Billions Euros, respectively. ${ }^{4}$ We argue that these financial difficulties are the direct consequence of the competitive interaction between clubs.

Our intention is to assess empirically how the amount of rent-seeking expenditure supported by clubs depends on several relevant features that characterized the football industry. To do so, we consider a simultaneous system of three wage - result - demand equations. Such a procedure allows accounting for the constraints impinging on the activity of each club. We choose moreover to approach the definition of the wage equation through the window of the stochastic frontiers literature. ${ }^{5}$ This implies considering a football club as a production unit involved in a production process whose ingredients such as the production itself and the inputs have to be identified. This is an interesting task in the particular context of the sport industry. Once the production process is identified, a wage frontier defining a relationship between a production level and the minimal average wage that allows the producer to reach the required production level can be determined. ${ }^{6}$ The frontier thus provides us with a one to one relationship between, on one hand, a specific result made by a club under certain conditions, and a theoretical average wage on the other hand. Considering all the production units competing inside a specific league allows us to identify this frontier. We argue then that the distance between such frontier and the individual and observable average wage of a club provides a direct measure of the amount of expenditures of this club that produces no relative gain in performance, but 
is supported at the equilibrium. We call such expenditure the individual wage distortion above the industry's frontier. In the context of the football industry, estimating an average wage frontier entails disentangling the minimum average wage that allows the football clubs to reach their production levels relative to the other competitor in the industry (i.e., their relative performances), from the part of the average wage due to the rent-seeking behavior of clubs in the vain attempt to enhance their relative position in the competition. This paper proposes an empirical evaluation of the industry's global distortion as well as individual assessments for each club.

A possible drawback of this study is the highly aggregated nature of the data available. This is particularly true for financial data. The sources of revenue of a football club, as well as the different parts constituting its global budget are difficult to observe. Note for instance that we use a measure of club average wage that aggregates the wages of the players of the same team, as well as the wages of players and non-players inside a team. On one hand, vertical wage aggregation inside the club should be a minor problem since non-players represent a small share of the total wage bill (less than $5 \%$ over the period observed. Source: Liga Nacional de Fútbol Profesional). On the other hand, some clubs may be characterized by a highly heterogeneous wage distribution across players. Working at a more aggregate level constraints the structure of the economic model under consideration and reduces the information that could be obtained from it. However, considering a simultaneous system of wage, performance, and demand might be helpful in order to treat part of the endogeneity that affects the variables under the control of each production unit. This is the methodology that we consider here.

The Spanish industry serves as a support for our study. Its organization as well as the behavior of its clubs has been particularly appealing over the last decade, as argued in detail in what follows. The database includes observations for the forty clubs playing in first and second league over the period 1996-2002. The next section presents the model to be estimated. Section 3 describes the Spanish football industry in more details. Section 4 presents the data as well as the estimation procedure and the results. Section 5 proposes a discussion and Section 6 concludes.

\section{The model}


Our aim in this section is to construct a football wage, result, and demand system that can be applied to the Spanish industry. The estimation of the model will allow us to explore the structure of the industry and provide an individual measure of the rent-seeking distortion that affects the average wage of each club participating to the contest.

\section{Production and Costs}

Each football club is a production unit. The club produces a result $Y$ during the season. We need first to define the inputs that enter the production process. It is assumed that the result $Y$ depends on the average quality of each player. Following Hoen and Szymanski (1999) and Szymanski (2000), we suppose that the average quality and the average cost of the player are closely related. ${ }^{7}$ Considering that the cost of labor $w^{*}$ instead of the usual quantity of labor $L$ enters the production function is fair in the particular context of the football industry. The usual studies on production consider that firms are price takers and control for the quantity of labor in order to attain a particular production level. Such an approach does not fit the football industry. First, the firms may have sufficient power to affect the costs proposed at the equilibrium on the labor market. Second, given that the amount of players on the playground is restricted, it is well admitted that a higher number of players does not allow the teams to obtain better result. We therefore assume that what matters is the quality of the group of players and not its size. Beside the costs, the experience $K$ may be another good candidate to help producing a result. It is supposed to be fixed in the short run. The experience for each club will be measured by the number of years spent in first league and the number of years spent in second league. Note that a club with a long history in the first league is expected to have higher valuations of the prize it is competing for.

We also introduce a third term, namely $\mathcal{\varepsilon}$, to account for the unpredictable events, that are beyond the control of the club, and that might affect its result. Let $X$ be a vector of additional explanatory variables that will be emphasized at the moment of the estimation. We define then the production function of each unit as the following: 


$$
Y=f\left(w^{*}, K, X, t, \varepsilon \mid \beta\right),
$$

where $\beta$ is a vector of parameters describing the technology and $t$ is a trend.

From equation (1), we know that, to obtain the result $Y$, the manager must pay the relevant average cost (that is, buy the relevant average quality)

$$
w^{*}=f^{-1}(Y, K, X, t, \varepsilon \mid \beta) \text {. }
$$

We argue that an unobservable individual distortion $\theta$ affects the primal average cost $w^{*}$ of each club. This distortion results from the competitive interaction between clubs, which is taken as exogenous here; it does not improve their relative performance, but instead entails an upward cost distortion. As this term is unobservable, it needs to be evaluated through the estimation process. Hence, the observed average wage $w$ is

$$
w=w^{*} \exp (\theta)=f^{-1}(Y, K, X, t, \varepsilon \mid \beta) \exp (\theta) .
$$

Note that the introduction of a trend $t$ allows us to shed light on the propensity of the football technology to be more costly over the years. We expect $t$ to have a positive effect on the clubs' average wage $w$. The average wage equation given in (3) is a stochastic frontier that needs to be estimated.

The result $Y$ obtained by the club may itself depend on factors such as the characteristics of this club and the environment where the production process takes place, i.e., $Y$ may itself be endogenous. For instance, clubs performing better may be the ones with a higher share of foreign players, with a higher share of members of the national team, those with a new coach, or those facing a higher demand. All these variables may also affect the average wage and therefore need to be accounted for in separate equations. It is therefore proposed to estimate a result and a demand equation jointly with the wage equation. 


\section{Result and demand}

The relation between result $Y$ and demand $D$ in the football industry depends upon two effects that need to be considered.

On one hand, demand depends on the result of the team (see Szymanski and Smith, 1997, Hoen and Szymanski, 1999, and Dobson and Goddard, 2001). We expect the audience to be attracted by teams that are performing better during the season. Whether the players are foreigners or not, whether they play in national teams, the arrival of a new trainer, the number of the titles won by the club in the past are also features that are worth taking into account. It is important as well to consider the attractiveness of the team, which implies taking into account the fact that the team presents an offensive or defensive configuration. This effect can be captured through several variables like for instance the position of the players on the field or the number of goals scored. Finally, we expect the size of the "potential market" faced by each club to be another important ingredient to determine demand.

Note that our demand expression does not include a price variable. This is due to the absence of systematic information on prices for clubs in our database. We can only observe upper and lower bonds of seasonal tickets prices for first division only, and from 2000 to 2003 (our database includes clubs competing in first and second division form 1996 to 2003). Since data are scarce, and since prices are certainly endogenous, i.e., they may depend on the rent seeking activity of clubs, we remove the price variable from the demand equation. Note that this should not affect the estimation significantly since most empirical studies in football fail to find a significant relationship between prices and attendance, especially in samples with a short time dimension. ${ }^{8}$ The demand function is of the form

$$
D=D(Y, A, Z, S, t, \eta \mid \gamma)
$$


where $A$ and $Z$ denote attractiveness and characteristics of the team, $S$ is the size of the market, $\eta$ is an error term and $\gamma$ is a vector of parameters. We also introduce a trend whose effect on demand is expected to be positive, i.e., demand should be increasing from one year to the other. Increasing broadcasting of football matches has completely changed the size and composition of demand and revenues for football clubs. Starting mainly in the 80 s, the impact of television broadcasting has accelerated in the 90 s especially thanks to the advent of the pay-per-view televisions. The pay-perview system has determined a dramatic increase in market size for a single match.

On the other hand, the result $Y$ must be adjusted to the level of demand $D$, so the former is endogenous to the latter. We therefore assume that the result of a team is constrained by the size of its audience. The main motivation for such an assumption is that a larger audience generates larger revenues and more ambitious results. Here we simply introduce a reduced form of a dynamic and technical adjustment process between result $Y$ and demand $D$ that we specify as follows:

$$
Y=\phi(D, \rho \mid \delta)
$$

where $\rho$ is an error term and $\delta$ is a vector of parameters.

Note that the demand function in equation (4) is interpreted as a short-run demand since it takes the result $Y$ as given. By replacing $Y$ in this demand function by its expression in equation (5), we obtain a reduced form interpreted as the long run demand function, defined as

$$
D=\varphi(A, Z, S, t, \xi \mid d)
$$

where $\xi$ is an error term, which depends on $\rho$ and $\eta$, and $d$ is the final vector of parameters to be estimated. Estimating equations (5) and (6) avoids the simultaneity problem that exists between $D$ and $Y$.

We do not consider the effect of the uncertainty of outcome on demand. Several authors including Neale (1964) have noted the connection between uncertainty of outcome in sporting contests with their 
popularity. It is usually considered that uncertainty of outcome is due to a close championship race with several teams in contention or the absence of long run domination by a particular team. The main reason why uncertainty of outcome is discarded in this analysis is that the Spanish championship is probably the most unbalanced one of all major European Leagues. Between 1946 and 1999, Barcelona and Real Madrid won 39 titles out of 54. Moreover, from 1946 onwards, only 15 teams finished in the top three places and this is the smallest number among the major European football leagues. Over our period of observation, i.e., between 1996 and 2003, Real Madrid and Barcelona were ranked in the top two places $57 \%$ of the time. Moreover, over the same period, there was an average six points difference between the team ranked first and the one ranked second.

The next step consists in estimating equations (3), (5) and (6). Note that the whole model under consideration is sequential. Since the system gives rise to a block-recursive structure, each equation can be estimated separately. We turn now to the description of the Spanish industry and the data available.

\section{The Spanish industry}

The Spanish Professional league is a natural candidate for our purpose. Note first that the Spanish clubs have been among the most profligate ones regarding expenditures on wages and compensation fees. Table 1 shows two rankings of the highest wages given in Europe in 1999 and of the biggest compensation fees that have been paid ever.

Second, Spanish clubs are not present on the stock market yet, contrary to English clubs for instance, and this might have a significant impact on clubs policies. Apart from being a source of finance, the stock market also acts as a constraint on expenditures and losses, because clubs are responsible towards their shareholders. In Spain, an assembly composed of fellows supporting the team generally elects the president of the club. As the fellows care about sportive results rather than profits, it seems that non-pecuniary results are particularly important in the valuation of the prizes for Spanish clubs, exacerbating the rent seeking. Indeed, clubs presidents are pressed to raise expenditures 
levels in order to enroll the best players. This specific context is therefore particularly appropriated for our study.

Another interesting characteristic of the Spanish industry may lie in the fact that the ethnical and cultural pride of some of its clubs strengthens competitive and even aggressive behaviors on the labor demand side. The performance of the team assumes therefore a peculiar importance, as a matter of nationalistic pride, adding up to increase the valuation of the rent and the associated rent-seeking expenditure level.

Finally, the Spanish professional league seems to have fully accomplished the Bosman revolution since it is one of the most internationally open of the European Leagues: in 1999 only $61 \%$ of players were Spanish nationals. As a result, some of the best European and non-European players are participating to the Spanish competition which might be the strongest one in Europe.

\section{Estimation and results}

We present in this section the estimation of the system defined above and the estimation results. The variables entering the equations are first examined in more detail.

The system

The demand function is specified as

$$
\begin{aligned}
\ln D=d_{0}+d_{1} S Y S+d_{2} \ln G O A L+d_{3} S F O R+ \\
\quad+d_{4} S F O R W+d_{5} S N A T+d_{6} \text { TRAIN }+d_{7} \ln P O P+d_{8} t+\xi
\end{aligned}
$$

As said above, the variables to be considered in the demand function should be the size of the market, the attractiveness and the characteristics of the team.

The strategic scheme elected (SYS) and the number of goals scored during the season (GOAL) are used as proxies in order to evaluate the attractiveness of the team. There are mainly two types of strategic schemes implemented by teams: three forwards and three midfielders or two forwards and 
four midfielders. The variable SYS takes value one if the former strategy is implemented, and zero otherwise. We expect a more offensive strategy (i.e., with three forwards) to attract a larger audience. Likewise, we expect the numbers of goals scored to have a positive effect on demand.

There are several variables that can be viewed as good candidates to describe the characteristics of the team. First, foreign players playing outside their own country are typically highly skilled and have a significant influence on the performance of the team. Thus, we include two variables in (7) to consider the effects of foreign players on demand: SFOR is the share of foreign players and SFORW is the share of foreign players from outside Europe among the foreign players. These two variables should have a positive effect on demand. Second, Spanish players who are also members of the national team are also expected to have an ability that is higher than the average. Therefore, the share of such players $(S N A T)$ is also accounted for. We anticipate demand to be also positively influenced in this case. Third, we introduce a dummy variable (TRAIN) that takes value one if the trainer of the team is new, and zero otherwise. The manager is responsible for the training and the organization of the team. The presidents of the clubs decide on changing trainers when new (higher) results are in order. The audience is usually highly sensitive to such a decision and TRAIN should have a positive effect on demand.

The last explanatory variable is $P O P$. It denotes the size of the population of the city to which the club under consideration belongs. Obviously, teams representing large urban areas attract a larger audience. This variable acts as a proxy for the market size and thus we expect it to have a positive effect on demand.

The characterization of the endogenous variable $D$ is now required. The audience is roughly defined as the set of individuals supporting the team. It includes spectators attending the games in the stadium, those watching the games on television, but also people generally following the performance of the club through the media. To evaluate and measure the size of such an audience is a difficult task. However, a very useful proxy can be considered for that matter. We use the average effective attendance during the season as a proxy for general audience. Note that this allows us to take into account two individual effects. The first effect, denoted as the size effect, implies that a more popular team plays in a bigger stadium, which is consistent with a larger audience; it can be seen as a long-run 
effect. The second effect, denoted as the liking effect, is a short-run effect. It implies that the instantaneous attendance of the stadium gets close to full capacity when the team is performing well, which should be a clear indicator of how the general audience behaves along the season. Taken together, these two effects should be helpful for our purpose.

We turn now to the result equation. It is simply determined as

$$
\ln Y=\delta_{0}+\delta_{1} \ln \hat{D}+\rho
$$

Note that $\hat{D}$ is the predicted value of $D$ obtained from the estimation of equation (7). We need to define a measure of the variable $Y$. The result of the club is measured by an index of actual performance of this club along the season. A simple and fair instrument is the number of points obtained by each team at the end of the season. Any victory is worth three points while a draw yields one point. All first league teams are credited a surplus of points equal to the total amount obtained by the best team of the second league at the end of the season. Doing so enables us to consider the forty teams simultaneously, as if they all belonged to one single league.

The last equation to be estimated is the average wage function. It is defined as

$$
\begin{array}{r}
\ln w=\beta_{0}+\beta_{1} \ln \hat{Y}+\beta_{2} D I V+\beta_{3} \ln U E F A+\beta_{4} \ln K_{l}+ \\
+\beta_{5} \ln K_{2}+\beta_{6} \ln C A P S+\beta_{7} t+\theta+\varepsilon
\end{array}
$$

The average wage is measured by the annual total budget divided by the number of players. Note that total budget includes the total wage bill as well as depreciated fee expenditures that must be paid in order to purchase players from other clubs.

Several explanatory variables are required to identify individual distortions above the wage frontier from the effects that are responsible for rent-seeking expenditures and are common to the whole industry. The right side of Equation (9) includes the number of players $L$, the result $Y$, and the experience $K$. Note that we use the predicted result $\hat{Y}$ obtained from the estimation of equation (8). 
The experience $K$ is decomposed into two variables. The first one, $K_{1}$, denotes the number of years spent in first league while $K_{2}$ indicates the number of years spent in second league. We expect these two variables to have opposite effects on clubs expenditures. Indeed, the valuation of the prize by teams' presidents, and thus, their behavior regarding expenditures should depend on the history of the performance of the club since its creation. For instance, a club with a long history in the first league is expected to have higher valuations, thus, higher long run results and larger wages. Likewise, a club, which spent most of his history in second league, may not be able and/or willing to afford high expenses.

Besides result and experience, we introduce additional variables in order to capture part of the heterogeneity among production units. The first one (UEFA) is a dummy variable that takes value one if the team simultaneously competes in the European league, and zero otherwise. This variable should have a positive influence on wages since being committed on two fronts needs additional units of talents. Another variable of interest is $C A P S$, which measures the number of times the players of the team have been enrolled in their respective national squad. This variable enables us to control for the quality of the players enrolled in the team and it should also have a positive effect on wages. Besides, we use a dummy variable (DIV) that takes value one if the team is competing in first division, and zero otherwise. This variable should most certainly have a positive effect on wages. Finally a trend $t$ is introduced.

\section{Data}

In order to test the economic model, we need data on the financial performance of the clubs as well as data on the supply and demand of the industry. The database is constructed using the annual data collection edited by the Spanish sport newspaper Marca. The collection dates back to the beginning of the nineties but relevant information regarding clubs competing in the Second league could only been obtained from 1996. Therefore, our sample includes information on all clubs of First and Second league starting with the 1996-1997 season up to the 2002-2003 season, which represents seven years of observation. Marca is a rich source of data regarding clubs budgets as well as players and teams 
characteristics and performances, stadiums affluences, clubs' historical course etc. The First league embraces twenty clubs while the Second League may include twenty or twenty-two clubs. At the end of each season, the three clubs ranked at the bottom of First League go down to Second League. Likewise, the four worst clubs of Second League are relegated to Third League and the three best clubs are promoted to First League.

Note that two samples will be considered: The first one is an unbalanced panel, which includes 281 observations. Some clubs may disappear from one year to the other, i.e., may go down to Third League and hence may disappear from the sample while new ones may appear since some Third League clubs are promoted and ascend to Second League. The result is a database of fifty different clubs that are not necessarily observed seven times over the period. The second sample that will be considered is a balanced panel. Considering simultaneously a balanced panel allows us to drop all the clubs that compete in Third League at least once during the period of observation and thus reduce the heterogeneity among the economic agents. The balanced panel includes observations on 28 clubs observed seven times over the period. In order to complete the database, the data on urban areas' population (variable $P O P$ in equation 7) has been collected from the website of the Instituto Nacional de Estatisticas (INE) ${ }^{9}$

Summary statistics regarding the variables are provided in Table 2.

\section{Estimation}

The system to be estimated is made of equations (7), (8) and (9). Since it is sequential, the three expressions can be estimated separately. The three error terms $\xi, \rho$ and $\varepsilon$ are supposed to be independent and to have a normal density function (with mean 0 and respective variances $\sigma_{\xi}^{2}, \sigma_{\rho}^{2}$ and $\sigma_{\varepsilon}^{2}$.) Maximum likelihood applied to equations (7) and (8) does not require additional specifications. However, when estimating the cost function expressed in (9), a difficulty arises due to the fact that the term $\theta$ is unobservable. We will assume that $\theta$ is characterized by a density function $f(\theta)$ defined over an interval $[0, \infty)$ 
The error structure $u=\theta+\varepsilon$ adopted in (9) follows a Panel Data specification where $\varepsilon$ are assumed to be i.i.d. $N\left(0, \sigma_{\varepsilon}^{2}\right)$ and $\theta$ is a non-negative term accounting for distortions above the theoretical frontier. ${ }^{10}$

We need now to say something about the density $f(\theta)$ and the way the estimation is performed. Denoting as $t=1, \ldots, T$ and $i=1, \ldots, N$, the subscripts for time and clubs respectively, five different procedures of estimation are considered:

(i) The first procedure considers that the $\theta \mathrm{s}$ are constant over time but vary across clubs. Moreover, the density $f(\theta)$ is half normal, i.e., the $\theta_{i}$ are i.i.d $N^{+}\left(0, \sigma_{\theta}^{2}\right)$.

(ii) The second procedure is similar to the previous one except that the density $f(\theta)$ is Truncated normal, i.e., the $\theta_{i}$ are i.i.d $N^{+}\left(\mu, \sigma_{\theta}^{2}\right)$. This allows the distribution to have a nonzero mode and provides a somewhat more flexible representation of the pattern of the distortion $\theta$ in the data. Note that an additional parameter $\mu$ needs then to be estimated.

(iii) The third procedure assumes that the $\theta$ s differ from one club to the other and vary systematically with time. They are of the form $\theta_{i t}=\theta_{i} \exp (-\eta(t-T))$ and are assumed to be i.i.d as truncations at 0 of the $N^{+}\left(0, \sigma_{\theta}^{2}\right)$ distribution. Note that this specification requires an additional parameter $\eta$, identical for all clubs, to be estimated.

(iv) The next procedure is similar to the previous one except that the density $f(\theta)$ is Truncated normal, i.e., the $\theta_{i}$ are i.i.d $N^{+}\left(\mu, \sigma_{\theta}^{2}\right)$.

(v) Note that the four previous specifications require the $\varepsilon_{i t}$ and the $\theta_{i}$ to be distributed independently of each other, and of the regressors. Moreover, specific distributional forms are necessary for $\theta$. These two constraints can be relaxed if the $\theta_{i}$ are considered as fixed effects. This procedure can be performed through the estimation of a different constant $\beta_{0 i}$ for each club. This approach is interesting in the sense that the assumption that the distortion $\theta_{i}$ may not be independent from the result $Y$ should not be discarded. Moreover, this is an additional mean to provide more evidence on the 
robustness of the results since the chosen distributional form for $\theta$ may influence the individual estimates $\hat{\theta}_{i}$.

The results of the different estimations are presented below. Three types of comments are worth emphasizing. First, since two databases are considered, we specify ten different sets of results for the estimation of the wage function. ${ }^{11}$ Our aim is to show that the estimation results regarding the distortions $\theta$ s are robust to the nature of the dataset and the type of estimation considered.

Second, note that with panel data, the estimator is able to distinguish each club's individual persistence from statistical noise. Therefore, the realization of $\theta_{i}$ for a particular firm can be identified, thus overcoming the limitation of a cross-section from which one can only identify the expectation of $\theta_{i}$ conditional on statistical noise (see Sickles, 2003 for a discussion of this issue).

Finally, note that the identification of the theoretical frontier $w^{*}=f^{-1}(Y, K, X, t, \varepsilon \mid \beta)$ requires observing some clubs that are not affected by rent dissipation. Hence, absolute rent dissipation values are obtained instead of relative values. We believe that accounting for second division clubs is helpful on that matter. Moreover, among the clubs competing in the first League are the ones from the Basque country (one of the Spanish provinces). These clubs have the particularity of mostly enrolling Basque players, the most extreme case being Athletic Club from Bilbao hiring only players from its own province. We are confident that, in this latter case, rent dissipation activity is almost nil, as will be confirmed in the results presented in the next section.

\section{Results}

The results are reproduced in Tables 3 and 4 . We present first the ones on the demand and result equations.

Consider the result equation. The R-squared is equal to 0.559 ( 0.549 respectively) if the unbalanced panel (balanced respectively) is taken into consideration. All the parameters are strongly significant. The result suggests that performance is affected by the size of the audience. Moreover, the nature of the dataset considered does not affect the demand elasticity of performance in a significant manner. 
Consider now the demand equation. The R-squared ( 0.940 if the panel is unbalanced and 0.878 if the panel is balanced) suggests that the variables selected strongly explain the size of the audience. A first set of results goes along with the initial intuition. Thus, demand significantly increases with the number of goals scored $(G O A L) .{ }^{12}$ Moreover, it is positively affected if the club strategy responds to a more offensive profile (SYS takes value one). ${ }^{13}$ This suggests that the audience increases if the team considered presents a higher offensive profile.

Unsurprisingly, the characteristics of the squad enrolled in the club are essential to explain demand. The audience responds positively and significantly to a higher share of players with experience in the national team of their country of origin (SNAT). This latter variable is a good candidate to account for quality in the team. A striking result also comes from the variables related to the national identity of players. The estimation sheds light on the fact that the share of players $(S F O R)$ from outside Spain sways negatively demand. It should be noted however that the parameter for SFOR is only significant at $10 \%$ in the balanced panel, while it is not significant in the unbalanced one. Moreover, if the share of players from outside Europe among foreign players $(S F O R W)$ is higher, then demand is positively and significantly affected. These two results may suggest the following: First, the audience may have a preference for Spanish players. Second, most non-European players of the Spanish league come from South America, and, in the view of the audience, such players may be culturally similar to Spanish players and may not alter the national identity of the club. Another possible explanation relies on the supposed comparative advantage of the different types of players. Again, in the view of the audience, South American players convey the idea of an entertaining and attractive way of playing, which is not necessarily associated with continental European players.

The population size of the city $(P O P)$ from which the club originates has a positive and significant effect on demand. Likewise, demand increases over time, as indicated by the positive parameter of the trend $t$. Finally, note that the coefficient of TRAIN is not significant in any of the estimations. Contrary to what has been predicted, the latter suggests that our databases do not provide any empirical evidence regarding the way demand is affected by the hiring of a new trainer.

We focus now on the wage expression. Table 4 presents six different sets of results where the following distinctions are made: (1) The panel is unbalanced, the $\theta$ s are constant over time but vary 
across clubs, and the density $f(\theta)$ is half normal. (2) The panel is unbalanced, the $\theta$ s differ from one club to the other and vary systematically with time, and the density $f(\theta)$ is half normal. (3) The panel is unbalanced and the $\theta \mathrm{s}$ are treated as fixed effects. (4) The panel is balanced, the $\theta \mathrm{s}$ are constant over time but vary across clubs, and the density $f(\theta)$ is half normal. (5) The panel is balanced, the $\theta \mathrm{s}$ differ from one club to the other and vary systematically with time, and the density $f(\theta)$ is half normal. (6) The panel is balanced and the $\theta \mathrm{s}$ are treated as fixed effects. In the course of the estimation it appeared that the parameter $\mu$ was never statistically different from 0 . We therefore discarded the truncated normal distributions and rather focus on half normal ones.

We observe only small deviations of the parameters values across the different sets of results. As expected, the coefficient of $\hat{Y}$ is always positive and significant, which implies that a higher performance requires a greater wage. Note that a $1 \%$ increase in performance requires a less than $1 \%$ increase in wages, meaning that the industry is characterized by economies of scale. The parameters of $K_{1}$ and $K_{2}$ are always positive and negative, respectively, and significant. This confirms that the history of the club performance matters when defining the wage. As explained previously, the director of the production process is more inclined to set up a large average wage if the club performed well in the past. On the other hand, weak performances in the past act as a break upon results. The parameters of UEFA are all positive and significant. This suggests that the average wage is higher if the club is involved simultaneously in the European championship. Surprisingly, the coefficient of CAPS turned out to be non-significant and failed to act as a variable that accounts for quality in the team. Note however that the coefficients of CAPS are positive as expected. The variable $D I V$ that takes value 1 if the club competes in First League and 0 otherwise presents a positive and significant parameter in all the models. This entails that the average wage is higher when the clubs compete in first division. Note also that the parameter of the trend $t$ is positive implying that the average wage of the whole industry is increasing over time.

Finally, the parameter $\eta$ is negative and significant. This is an interesting result, which shows that the clubs' wage distortions over the theoretical frontier follow a systematic and significant increase over time. This suggests that the overall value of the Spanish football league as well as the valuation of 
the prizes by clubs have increased, as indicated by the theory. The average increase from one year to the other is estimated to be close to $6 \%$, regardless of which database is considered. A simple likelihood ratio test allows testing model (2) against model (1) and model (5) against model (4). The LR test statistic is equal to 4 (3.2 respectively) if the panel is unbalanced (balanced respectively), which confirms that the model that allows $\theta$ to increase over time is preferred to a model where $\theta$ remains constant over time. ${ }^{14}$

\section{Evaluating individual wage distortions}

From the estimation of the three equations system, predictions of individual wage distortion parameters $\theta$ can be recovered using the procedures initiated by Hausman and Taylor (1981) and Battese and Coelli (1988). The wage distortion over the theoretical frontier is simply defined as $\exp (\theta)$

Table 5 provides estimates of the individual $\exp \left(\theta_{i}\right)$. Five sets of results are presented; they are associated to the models (1)-(5) defined above. Note that specification (6) has been discarded since the constant and the output parameter are not significant and this may alter the validity of our estimates. ${ }^{15}$

Several results are worth emphasizing. First, note that the estimation results are usually robust to the nature of the estimation procedure or the dataset under consideration. They show little differences with respect to the ranking of the clubs and the evaluation of their individual distortion. Second, 10 to $16 \%$ of clubs in the unbalanced sample ( $18 \%$ to $21.4 \%$ in the balanced one) have a distortion greater than 2, i.e., their observed average wage is more than twice higher than the theoretical wage predicted by their performance. This suggests a strong discrepancy between a few firms that can support heavy distortions of their expenses and the others that suffer from higher financial constraints. Unsurprisingly, the most famous clubs in the history of the Spanish league belong to this first group with the highest distortion, signaling a more active rent-seeking activity. Third, notice that First League and Second League clubs can be indifferently found along the different positions of the five 
different ranking, suggesting that there is no clear persistence in the relationship between each league and the wage distortions of the clubs.

Finally, consider the unbalanced panel. ${ }^{16}$ The means for the average club of the sample range from 1.452 to 1.525 , i.e., the distortion of the average firm lies from 45.2 to $52.5 \%$ above the frontier. The average club supports a budget of 19.8 millions Euros over the period. ${ }^{17}$ This implies that such a club bears an absolute distortion of 6.1 to 6.8 millions Euros above the theoretical frontier. Note that this club would have reached the same performance if no distortion had been dissipated, i.e., with a budget that ranges from 13 to 13.7 millions Euros. A similar remark can be provided for the whole Spanish football industry. Consider for instance the last year of observation, i.e., the 2002-2003 season. The whole industry supported during this period a total budget of 1.182 Billion Euros, while the total distortion above the theoretical frontier ranged from 368 to 407 millions Euros, depending on whether estimation procedures (1), (2) or (3) are considered. Again, all the clubs of both First and Second League would have reached the same performance if these distortions had not been dissipated.

\section{Conclusion}

Considering simultaneously the demand, the result, and the average wage of football clubs performing in the Spanish league has allowed us to obtain interesting results regarding the structure of the industry and the financial results of these clubs.

First, the parameters of the variables of interest are usually significant and have the expected signs; individual estimates of wage distortions go well with basic intuitions. This suggests that the methodology chosen in this paper presents some empirical relevance.

Second, the empirical results have shed light on important wages and budget distortions faced by clubs competing in the industry for the different prizes. The estimated budget distortion in nominal terms during the 2002-2003 season amounts to a stunning figure of 368 to 407 millions Euros. It seems that rent-dissipation is particularly high for the Spanish football industry, in accordance with casual observation of losses and debts of football teams. 
The results in this paper illustrate well the importance of the financial difficulty faced by many clubs in the Spanish industry and other European countries at the end of 2003. A recent special issue of the Journal of Sport Economics (volume 7, number 1) on a potential financial crisis in the European football industry sheds light on this issue. In particular, it seems to be well admitted that many clubs in Europe are facing an imbalance between incomes and expenditures, as well as a rising debt. This is particularly true for small and large clubs in Italy, and small clubs in England, Scotland, Belgium, and Portugal. Note that observing small clubs facing financial deficits goes in line with our result that wage distortion affects clubs from any division or any position in the final ranking of the championship. Paradoxically, the main cause of the financial crisis in these clubs has been the increasing amount of income entering the game, from television and other sources.

There may be several solutions to such crisis: First, following the tight regulation that has been practiced in France, the Union of European Football Associations could for instance require from clubs annual audited financial statements, or proofs that clubs have no overdue payments for transfer activities or no payment owning to employees. The Union could condition the participation of clubs to European competitions on the respect of these criteria. A second possible solution is to adopt American practices: American major leagues such as basketball, baseball or American football are usually financially stable organizations. They implement several regulatory mechanisms such as salary caps, draft rules, or revenue sharing and redistribution rules. Redistribution rules is maybe the most appealing scheme but is currently difficult to put into practice in Europe since clubs are facing the punishment of being relegated to a lower division. Hence, the European football industry may have to restructure its competition framework and may impose greater restrictions on the mobility of clubs between upper and lower divisions.

\section{References}

Battese, G.E., and T.J. Coelli, 1988, Prediction of Firm-Level Technical Efficiencies with a Generalized Frontier Production Function and Panel Data, Journal of Econometrics, 38, 387-399. 
Chung, T.Y., 1996, Rent-Seeking Contest when the Prize Increases with Aggregate Efforts, Public Choice, 87, 55-66.

Clark, D.J., and Riis, C., 1996, A Multi-Winner Nested rent-Seeking Contest, Public Choice, 87, 177184.

Clark, D.J., and Riis, C., 1998, Influence and the Discretionary Allocation of Several Prizes, European Journal of Political Economy, 14, 605-625.

Dobson, S. and Goddard, J., 2001, The Economics of Football, Cambridge University Press, Cambridge, UK.

Fort, R., and Quirk, J., 2002, Owner Results and Competitive Balance, mimeo.

Hausman, J.A., and W.E. Taylor, 1981, Panel Data and Unobservable Individual Effects, Econometrica, 49, 1377-1398.

Hillman, A.L., and Riley J.G., 1989, Politically Contestable Rents and Transfers, Public Choice, 1, 1739.

Hoen, T., and Szymanski, S., 1999, The Americanization of European Football, Economic Policy, 205-33.

Hofler, R.A, and J.E. Payne, 1996, How Close to their Offensive Potential do Football Teams Play? Applied Economic Letters, 3, 743-747.

Hofler, R.A, and J.E. Payne, 1997, Measuring Efficiency in the National Basketball Association, Economics Letters, 55, 293-299.

Kumbhakar, S.C., and C.A.K. Lovell, 2000, Stochastic Frontier Analysis, Cambridge University Press, Cambridge, UK.

Neale, W.C., 1964, The Peculiar Economics of Professional Sports, Quarterly Journal of Economics, $78,1-14$

Nti, K.O., 1999, Rent-Seeking with Asymmetric Valuations, Public Choice, 75, 415-430.

Rosen, S., 1981, The Economics of Superstar, American Economic Review, 71, 845-58.

Rosen, S., and A. Sanderson, 2001, Labor Market in Professional Sports, Economic Journal, 111, 4768.

Rottenberg, S., 1956, The Baseball Players Labor Market, Journal of Political Economy, 64, 242-58. 
Sickles, R.C., 2003, Panel Estimators and the Identification of Firm-Specific Efficiency Levels in Parametric, Semiparametric and Nonparametric Settings, mimeo.

Sloane, P., 1971, The Economics of Professional Football: The Football Club as Utility Maximiser, Scottish Journal of Political Economy, 17, 121-46.

Stein, W.E., 2002, Asymmetric Rent-Seeking with More than Two Contestants, Public Choice, 113, 325-336.

Szymanski, S., 2000, A Market Test for Discrimination in the English Professional Soccer Leagues, Journal of Political Economy, 108, 590-603.

Szymanski, S., 2002, The Economic Design of Sporting Contest: A Review, mimeo, Imperial College, UK.

Szymanski, S. and Smith, R., 1997, The English Football Industry: Profit, Performance and Industrial Structure, International Review of Applied Economics, 11, 135-53.

Szymanski, S., and Valletti, T.M., 2003, First and Second Prizes in Imperfectly Discriminating Contests, mimeo, Imperial College, UK.

Tullock, G., 1980, Efficient Rent-Seeking, in J.M., Buchanan, R.D., Tollison and G. Tullock (Eds.), Toward a Theory of the Rent-Seekiing Society, College Station: Texas A\&M University Press.

\section{Notes}

1. In the symmetric setting of Tullock (1980), the individual effort (or rent-seeking expenditure) increases with the value of the prize, and decreases with the number of contestants. It is suggested that players are caught in a prisoner dilemma type of equilibrium, i.e., the probability of winning is the same for each player and is therefore independent from the level of effort provided at the equilibrium. From the point of view of the contestants, the least costly situation to be obtained is then the one were they are able to coordinate on a symmetric equilibrium with the lowest possible level of effort. Such equilibrium is not feasible since the strategic interaction among the players leads to a higher level of expenditure with no relative gain in performance. This model has then been extended in various ways. It has been suggested for instance that teams may have different valuations of the prize (Hillman and 
Riley, 1989; Nti, 1999; and Stein, 2002). Asymmetric valuations tend to generate a bias towards under-dissipation of the rent, making the total rent dissipation smaller than what could be obtained in a symmetric context. Likewise, competitors may be offered several prices simultaneously. Clark and Riis (1996 and 1998) show that in a multiple prize and symmetric players setting, the amount of rent seeking is reduced compared to a situation where there is a unique price. Finally, the value of the prize clubs are competing for may itself be endogenous. Chung (1996) for instance proposes a framework where the value of the prize increases with the effort spent by all the participants.

Contexts as different as economic organizations, wars competition for natural monopoly, patent races, political rent seeking, and sport competitions can be described as contests where players spend resources to win a price. Rent seeking with asymmetric valuations of the price is probably the most common situation encountered in practice. Political candidates competing to win an election or employees struggling for a job promotion are potential examples. Each competitor may have a private valuation of the price, which may depend on his/her own characteristics and/or experience. This feature is also the most common in sport competition: A club/player that has just been promoted to first division may have a different valuation of a top position in the ranking than an experienced club, which has been competing for years to obtain it. Likewise, sport disciplines, such as basketball or football, which imply promotion, relegation, or qualification for a European competition, are all examples of simultaneous contests where competitors may be offered several prices simultaneously (win the championship, avoid relegation, qualify for the European cup for instance). In multi-stage contests, such as tennis championship, players usually compete for a single price, i.e., the final victory in the tournament. Finally, $R \& D$ investment to obtain a monopoly right is an example of a case where the value of the prize firms are competing for is endogenous: In this case, the monopoly's profit increases with total investments. We are not aware of such endogenous prize framework in a sport competition environment.

2. Experts usually argue that there are two main reasons for such a decline. First, television channels, which have constituted the main source of clubs' revenues over the last ten years, are facing financial difficulties, or decide to reduce significantly their expenditures on football broadcasting. This is the case of Via Digital or Canal Plus in Spain, RAI in Italy, ITV Digital in England, and Kirch in 
Germany. Second, the introduction of the Bosman law in 1995 dramatically changed the European football labor market regulations. Before 1995, any club willing to hire a player had to pay a compensation fee to the former club even if the contract had expired. Hence, even out-of-contract players were not completely free to leave their employer. Moreover, the clubs were not allowed to employ more than three players coming from abroad. The clubs had strong bargaining power since they could prevent a player from changing team if the compensation fee did not satisfy them. The situation was very much alike the case of clubs' monopsony power described by Rottenberg (1956) in the baseball industry. Since 1995, an out-of-contract player can freely negotiate with a team and does not have to pay any compensation fee to his former club. The clubs now anticipate this new ingredient and provide the players with incentives to sign long-term contracts. The main consequence has been that the compensation fees and players' wages have greatly increased since 1995 .

Taken together, these two effects had important consequences on clubs' liability. Since clubs are loosing their most lucrative source of revenue, they are not capable of handling the explosion of their budgets and the growing increase of players' wages.

3. See for instance the interview of Galliani (vice president of A.C. Milan and president of the Italian Football League) who advocates salary caps in the Corriere della Sera, $18^{\text {th }}$ of May 2002. Moreover, on 5th November 2002, the so-called G-14, a group of western Europe's biggest clubs, met in Brussels to draw up new rules and proposed that from 2005 its members restrict their salary bills to $70 \%$ of the club's turnover.

4. These data have been collected in El País, $28^{\text {th }}$ of August 2002, L'Equipe, $23^{\text {rd }}$ of October 2002 and Repubblica $8^{\text {th }}$ of June 2003.

5. The stochastic frontier analysis is frequently used in sport economics, see for instance Hofler and Payne (1996 and 1997), or the chapter 5 in Dobson and Goddard (2000) for a survey. Data Envelopment Analysis (DEA) may be another potential technique although it is less often employed in sport economics. Note that it is usually considered that the stochastic approach is more applicable in situations where measurement errors and random effects influence the data, as it is the case in our study. Although some recent developments in stochastic DEA have attempted to address the issue of 
DEA being non-stochastic, we choose in this paper a broadly parametric approach for ease of exposition, given that we use a three equations structure.

6. It is usually suggested that European football clubs depart from sport professional clubs in the U.S. in the sense that they care more about their ranking in the national championship than their profit. Professional teams in the U.S. are usually thought as profit maximizers, while European clubs may only be performance seekers in sport competition. This idea goes back to the seminal contributions of Rottenberg (1956), Neale (1964) and Sloane (1971) and has been more recently advocated by Szymanski and Smith (1997).

7. Note that, as suggested by an anonymous referee, we assume away rent seeking on the part of the players. The "superstar effect" as defined by Rosen (1981) may provide some players with a higher bargaining power at the moment of determining individual wages, and may therefore affect the rent dissipation by clubs and/or the estimated wage frontier. A database including observations of several European leagues could allow evaluating for instance how the wage frontier of each national industry depends on the star player to average player ratio in each country. We leave this concern for future research.

8. "In general, match-attendance models tend to have difficulty in identifying a relationship between variables such as admission prices [...] and attendances." (Dobson and Gerrard, 2001, p. 326).

9. www.ine.es.

10. A survey of references on this issue can be found in Kumbhakar and Lovell (2000). All models were estimated using the FRONTIER41 software, written by Tim Coelli.

11. Note that while presenting the results, it will be suggested that $\mu$ is never statistically different from 0 . The models considering truncated normal distributions will then be discarded and only six sets of results will be presented.

12. We also tested the effect of the lagged $G O A L_{\mathrm{t}-1}$ on demand. The results suggested that $G O A L_{\mathrm{t}-1}$ had a lower and less significant impact on demand than $G O A L_{\mathrm{t}}$. Note that football demand in Spain is highly sensitive to current performance, as suggested by very frequent instantaneous drops in demand for clubs performing badly, even if they have a prestigious historical performance record. Moreover, an additional variable, VIC, namely the number of victories obtained during the season, also had a 
positive effect on demand. However it presented strong evidence of correlation with the number of goals scored and has therefore been discarded.

13. Note however that the effect of SYS is globally insignificant. This is probably due to the fact that our aggregate measure shows little variance and partially fails to account for the subtle difference of strategies across clubs.

14. The levels of significance are 5\% and 10\% (unbalanced and balanced panel respectively).

15. The fixed-effect specification uses the constant as the reference to evaluate firms' individual effects.

16. Results on the balanced sample are available upon request.

17. The budget is just defined as the average wage times the number of players enrolled in the club.

\section{Tables}

Table 1: Wages and compensation fees

\begin{tabular}{lrll}
\hline \multicolumn{1}{c}{$\begin{array}{c}\text { Wages, 1999 } \\
\text { (per week, in Euros) }\end{array}$} & \multicolumn{2}{c}{$\begin{array}{c}\text { Compensation fees } \\
\text { (up to 2002 in Euros) }\end{array}$} \\
\hline 1. Del Piero (Italy) & 114,922 & 1. Zidane (Spain) & $75,100,000$ \\
2. McManaman (Spain) & 108,537 & 2. Figo (Spain) & $61,400,000$ \\
3. Kluivert (Spain) & 95,769 & 3. Crespo (Italy) & $59,760,000$ \\
4. Anelka (Spain) & 92,576 & 4. Vieri (Italy) & $51,460,000$ \\
5. Vieri (Italy) & 92,576 & 5. Mendieta (Italy) & $48,000,000$ \\
6. Ronaldo (Italy) & 83,000 & 6. Ferdinand (England) & $46,800,000$ \\
7. Effenberg (Germany) & 79,806 & 7. Overmars (Spain) & $41,500,000$ \\
8. Balakov (Germany) & 79,806 & 8. Anelka (Spain) & $39,000,000$ \\
9. Elber (Germany) & 54,269 & & \\
10. Shearer (England) & 46,480 & & \\
11. Owen (England) & 39,840 & & \\
\hline Source: Dobson and Gerrad (2001) and El País, 28 th of August 2002.
\end{tabular}


Table 2: Summary of variables (Statistics of the Unbalanced Panel)

\begin{tabular}{|c|c|c|c|}
\hline Variable & Description & Mean & Standard Deviation \\
\hline$w$ & Average wage in Euros & 875,496 & $1,465,913$ \\
\hline$Y$ & $\begin{array}{l}\text { result measured as the number of points obtained } \\
\text { over the season }\end{array}$ & 93.5 & 41.4 \\
\hline$K_{l}$ & Years spent in first league & 23.9 & 25.1 \\
\hline$K_{2}$ & Years spent in second league & 17.6 & 12.4 \\
\hline$U E F A$ & $\begin{array}{l}\text { Takes value } 1 \text { if the team simultaneously } \\
\text { competes in the European cup, } 0 \text { otherwise }\end{array}$ & 0.178 & \\
\hline CAPS & $\begin{array}{l}\text { Total number of caps in the national team (all } \\
\text { players taken together) }\end{array}$ & 87.6 & 142.6 \\
\hline$D$ & Demand, effective audience as a year average & 17,143 & 17.154 \\
\hline$S Y S$ & $\begin{array}{l}\text { Takes value one if the team is organized as } 4-3-3 \\
\text { (four defenders, three midfields and } 3 \text { forwards), } \\
0 \text { otherwise }\end{array}$ & 0.110 & \\
\hline SFOR & Share of foreign players in the team & 0.254 & \\
\hline SFORW & $\begin{array}{l}\text { Share of foreign players from outside Europe } \\
\text { among the foreign players }\end{array}$ & 0.586 & \\
\hline$G O A L$ & Number of goals scored over the season & 49.5 & 12.6 \\
\hline SNAT & Share of players enrolled in a national team & 0.184 & \\
\hline TRAIN & Takes value 1 if the trainer is new, 0 otherwise & 0.459 & \\
\hline VICTO & Number of victories obtained & 14.3 & 4.9 \\
\hline$D I V$ & $\begin{array}{l}\text { Takes value } 1 \text { if team plays in First league, } 0 \\
\text { otherwise }\end{array}$ & 0.500 & \\
\hline$P O P$ & $\begin{array}{l}\text { Population size of the community the club } \\
\text { belongs to }\end{array}$ & 523,458 & 800,464 \\
\hline
\end{tabular}


Table 3: Estimation Results: Result and Demand

\begin{tabular}{lll}
\hline Parameter & Unbalanced Panel & Balanced Panel \\
\hline \hline
\end{tabular}

Result

$\begin{array}{ccc}\text { Constant } & 3.381^{\mathrm{a}} & 3.522^{\mathrm{a}} \\ & (0.058) & (0.072) \\ \hat{D} & 0.434^{\mathrm{a}} & 0.391^{\mathrm{a}} \\ & (0.021) & (0.024) \\ \sigma_{\rho} & 0.304^{\mathrm{a}} & 0.268^{\mathrm{a}} \\ & (0.012) & (0.013) \\ & & \\ R^{2} & 0.559 & 0.549\end{array}$

Demand

$\begin{array}{ccc}\text { Constant } & -2.378^{\mathrm{a}} & -2.824^{\mathrm{a}} \\ & (0.5675) & (0.682) \\ \text { SYS } & 0.143 & 0.178^{\mathrm{c}} \\ & (0.100) & (0.107) \\ \text { SFOR } & -0.266 & -0.538^{\mathrm{c}} \\ & (0.243) & (0.285) \\ \text { SFORW } & 0.245^{\mathrm{b}} & 0.560^{\mathrm{a}} \\ & (0.105) & (0.136) \\ \text { GOAL } & 0.738^{\mathrm{a}} & 0.896^{\mathrm{a}} \\ & (0.151) & (0.180) \\ \text { SNAT } & 2.326^{\mathrm{a}} & 2.198^{\mathrm{a}} \\ & (0.197) & (0.214) \\ \text { TRAIN } & 0.002 & -0.034 \\ & (0.061) & (0.072) \\ \text { POP } & 0.225^{\mathrm{a}} & 0.185^{\mathrm{a}} \\ & (0.033) & (0.038) \\ T & 0.043^{\mathrm{a}} & 0.061^{\mathrm{a}} \\ & (0.016) & (0.019) \\ \sigma_{\xi} & 0.508^{\mathrm{a}} & 0.491^{\mathrm{a}} \\ & (0.021) & (0.025) \\ R^{2} & & \\ & & \end{array}$

Number of observations

281

196

Note: The Unbalanced Panel contains 50 clubs of first and second division observed over the period 1996-2003. The Balanced Panel includes 28 clubs observed over the same period. Standard errors are in parenthesis.

Significant at $1 \%(a), 5 \%(b)$, and $10 \%$ (c). 
Table 4: Estimation Results: Average wage

\begin{tabular}{|c|c|c|c|c|c|c|}
\hline \multirow[b]{2}{*}{ Parameters } & \multicolumn{3}{|c|}{ Unbalanced Panel } & \multicolumn{3}{|c|}{ Balanced Panel } \\
\hline & (1) & (2) & (3) & (4) & (5) & (6) \\
\hline Constant & $\begin{array}{c}0.105 \\
(0878)\end{array}$ & $\begin{array}{c}0.528 \\
(08800\end{array}$ & $\begin{array}{r}2.730^{\mathrm{a}} \\
0456\end{array}$ & $\begin{array}{c}-0.161 \\
(1075)\end{array}$ & $\begin{array}{c}0.392 \\
(1096)\end{array}$ & $1.136^{\mathrm{c}}$ \\
\hline$\hat{Y}$ & $\begin{array}{c}0.564^{\mathrm{a}} \\
(0.068)\end{array}$ & $\begin{array}{c}0.482^{\mathrm{a}} \\
(0.066)\end{array}$ & $\begin{array}{l}0.208^{\mathrm{a}} \\
(0.032)\end{array}$ & $\begin{array}{l}0.625^{\mathrm{a}} \\
(0.072)\end{array}$ & $\begin{array}{c}0.515^{\mathrm{a}} \\
(0.079)\end{array}$ & $\begin{array}{c}0.173^{\mathrm{a}} \\
(0.034)\end{array}$ \\
\hline$D I V$ & $\begin{array}{c}0.439^{\mathrm{a}} \\
(0.106)\end{array}$ & $\begin{array}{c}0.446^{\mathrm{a}} \\
(0.104)\end{array}$ & $\begin{array}{c}0.398^{\mathrm{a}} \\
(0.099)\end{array}$ & $\begin{array}{l}0.306^{\mathrm{b}} \\
(0.123)\end{array}$ & $\begin{array}{c}0.310^{\mathrm{b}} \\
(0.121)\end{array}$ & $\begin{array}{l}0.329^{\mathrm{a}} \\
(0.116)\end{array}$ \\
\hline$U E F A$ & $\begin{array}{c}0.182^{b} \\
(0.073)\end{array}$ & $\begin{array}{c}0.160^{\mathrm{b}} \\
(0.072)\end{array}$ & $\begin{array}{c}0.149^{\mathrm{b}} \\
(0.062)\end{array}$ & $\begin{array}{c}0.169^{\mathrm{b}} \\
(0.070)\end{array}$ & $\begin{array}{c}0.148^{\mathrm{b}} \\
(0.070)\end{array}$ & $\begin{array}{c}0.141^{\mathrm{b}} \\
(0.063)\end{array}$ \\
\hline$K_{l}$ & $\begin{array}{c}0.340^{\mathrm{a}} \\
(0.031)\end{array}$ & $\begin{array}{c}0.344^{\mathrm{a}} \\
(0.032)\end{array}$ & $\begin{array}{c}0.290^{\mathrm{a}} \\
(0.087)\end{array}$ & $\begin{array}{c}0.343^{\mathrm{a}} \\
(0.038)\end{array}$ & $\begin{array}{c}0.347^{\mathrm{a}} \\
(0.038)\end{array}$ & $\begin{array}{c}0.741^{\mathrm{a}} \\
(0.195)\end{array}$ \\
\hline$K_{2}$ & $\begin{array}{l}-0.093^{\mathrm{a}} \\
(0.034)\end{array}$ & $\begin{array}{l}-0.094^{\mathrm{a}} \\
(0.035)\end{array}$ & $\begin{array}{c}-0.147^{b} \\
(0.073)\end{array}$ & $\begin{array}{l}-0.124^{\mathrm{a}} \\
(0.038)\end{array}$ & $\begin{array}{l}-0.122^{\mathrm{a}} \\
(0.039)\end{array}$ & $\begin{array}{l}-0.150^{\mathrm{b}} \\
(0.075)\end{array}$ \\
\hline CAPS & $\begin{array}{c}0.030 \\
(0.028)\end{array}$ & $\begin{array}{c}0.029 \\
(0.028)\end{array}$ & $\begin{array}{c}0.028 \\
(0.025)\end{array}$ & $\begin{array}{c}0.049 \\
(0.031)\end{array}$ & $\begin{array}{c}0.050^{\mathrm{c}} \\
(0.030)\end{array}$ & $\begin{array}{c}0.039 \\
(0.029)\end{array}$ \\
\hline$t$ & $\begin{array}{c}0.104^{\mathrm{a}} \\
(0.010)\end{array}$ & $\begin{array}{c}0.083^{\mathrm{a}} \\
(0.015)\end{array}$ & $\begin{array}{c}0.111^{\mathrm{a}} \\
(0.009)\end{array}$ & $\begin{array}{c}0.120^{\mathrm{a}} \\
(0.011)\end{array}$ & $\begin{array}{c}0.098^{\mathrm{a}} \\
(0.016)\end{array}$ & $\begin{array}{c}0.109^{\mathrm{a}} \\
(0.011)\end{array}$ \\
\hline$\sigma_{\varepsilon}^{2}$ & $\begin{array}{c}0.278^{\mathrm{a}} \\
(0.057)\end{array}$ & $\begin{array}{c}0.380^{\mathrm{a}} \\
(0.103)\end{array}$ & $\begin{array}{l}0.270^{* a} \\
(0.011)\end{array}$ & $\begin{array}{c}0.321^{\mathrm{a}} \\
(0.087)\end{array}$ & $\begin{array}{c}0.446^{\mathrm{a}} \\
(0.149)\end{array}$ & $\begin{array}{l}0.271^{* a} \\
(0.013)\end{array}$ \\
\hline$\eta$ & - & $\begin{array}{l}-0.061^{\mathrm{b}} \\
(0.030)\end{array}$ & - & - & $\begin{array}{l}-0.057^{\mathrm{c}} \\
(0.030)\end{array}$ & - \\
\hline
\end{tabular}

Number of observations

$281 \quad 196$

\footnotetext{
Note: The Unbalanced Panel contains 50 clubs of first and second division observed over the period 1996-2003. The Balanced Panel includes 28 clubs observed over the same period.

(1) and (4): Half-Normal distribution, $\theta_{i}$ constant over time but varies across clubs.

(2) and (5): Half-Normal distribution, $\theta_{i t}$ varies over time and across clubs.

(3) and (6): Fixed effects technique: No distribution required, $\theta_{i}$ constant over time but varies across clubs. Standard errors are in parenthesis.

$\sigma_{\varepsilon}$.

Significant at $1 \%(\mathrm{a}), 5 \%(\mathrm{~b})$, and $10 \%(\mathrm{c})$.
} 
Table 5: Estimation Results: Efficiency $\exp (\theta)$

Unbalanced Panel

\begin{tabular}{|c|c|c|c|c|c|c|c|c|c|}
\hline \multicolumn{6}{|c|}{ Onoaranced rantel } & \multicolumn{4}{|c|}{ Daranced ranem } \\
\hline \multicolumn{2}{|c|}{ (1) } & \multicolumn{2}{|c|}{$(2)$} & \multicolumn{2}{|c|}{ (3) } & \multicolumn{2}{|c|}{ (4) } & \multicolumn{2}{|c|}{$(5)$} \\
\hline Tenerife & 3.059 & Tenerife & 3.135 & Tenerife & 3.662 & Tenerife & 3.153 & Tenerife & 3.189 \\
\hline Villareal & 2.608 & Real Madrid & 2.779 & Real Madrid & 3.177 & Villareal & 2.512 & Real Madrid & 2.659 \\
\hline Real Madrid & 2.429 & Villareal & 2.703 & Deportivo & 2.895 & Real Madrid & 2.341 & Villareal & 2.583 \\
\hline Deportivo & 2.070 & Barca & 2.316 & Barca & 2.583 & Deportivo & 2.204 & Deportivo & 2.325 \\
\hline Barca & 2.050 & Deportivo & 2.226 & Villareal & 2.347 & Alavés & 2.072 & Barca & 2.227 \\
\hline Málaga & 1.989 & Málaga & 2.041 & Málaga & 2.195 & Barca & 1.996 & Alavés & 2.110 \\
\hline Alavés & 1.950 & Alavés & 2.019 & Mallorca & 2.075 & Mallorca & 1.920 & Mallorca & 1.956 \\
\hline Mallorca & 1.842 & Mallorca & 1.899 & Alavés & 2.052 & Valencia & 1.578 & Valencia & 1.713 \\
\hline Xeres & 1.825 & Celta & 1.888 & Valencia & 1.902 & Rayo Val. & 1.479 & Rayo Val. & 1.549 \\
\hline Getafe & 1.650 & Xeres & 1.862 & At. Madrid & 1.775 & Salamanca & 1.478 & At. Madrid & 1.486 \\
\hline Merida & 1.626 & Valencia & 1.745 & Rayo Val. & 1.763 & Real Socied. & 1.377 & Salamanca & 1.446 \\
\hline Valencia & 1.591 & Getafe & 1.728 & Xeres & 1.723 & Celta & 1.368 & Celta & 1.418 \\
\hline Numancia & 1.548 & Merida & 1.577 & Getafe & 1.699 & At. Madrid & 1.367 & Real Socied. & 1.399 \\
\hline Extremadura & 1.530 & Numancia & 1.565 & Celta & 1.634 & Sporting & 1.347 & Sporting & 1.359 \\
\hline Salamanca & 1.497 & At. Madrid & 1.547 & Extremadura & 1.543 & Betis & 1.299 & Betis & 1.332 \\
\hline Lleida & 1.450 & Recreativo & 1.513 & Salamanca & 1.543 & Zaragoza & 1.287 & Zaragoza & 1.323 \\
\hline Recreativo & 1.437 & Extremadura & 1.505 & Lleida & 1.537 & Las Palmas & 1.247 & Valladolid & 1.286 \\
\hline Ecija & 1.410 & Salamanca & 1.485 & Merida & 1.516 & Badajoz & 1.236 & Racing San. & 1.275 \\
\hline At. Madrid & 1.400 & Rayo Val. & 1.452 & Real Socied. & 1.507 & Racing San. & 1.230 & Las Palmas & 1.241 \\
\hline Real Socied. & 1.381 & Real Socied. & 1.418 & Sporting & 1.484 & Albacete & 1.200 & Albacete & 1.163 \\
\hline Rayo Val. & 1.377 & Lleida & 1.413 & Betis & 1.481 & Oviedo & 1.174 & Oviedo & 1.163 \\
\hline Sporting & 1.372 & Sporting & 1.396 & Murcia & 1.464 & Leganés & 1.156 & Leganés & 1.147 \\
\hline Celta & 1.310 & Betis & 1.346 & Levante & 1.443 & Eibar & 1.142 & Eibar & 1.128 \\
\hline
\end{tabular}


Table 5 continued

\begin{tabular}{|c|c|c|c|c|c|c|c|c|c|}
\hline Betis & 1.300 & Ecija & 1.330 & Racing San. & 1.376 & Valladolid & 1.110 & At. Bilbao & 1.111 \\
\hline Las Palmas & 1.280 & Zaragoza & 1.328 & Numancia & 1.338 & At. Bilbao & 1.104 & Espanyol & 1.102 \\
\hline Levante & 1.280 & Levante & 1.321 & Leganés & 1.307 & Sevilla & 1.104 & Sevilla & 1.097 \\
\hline Zaragoza & 1.278 & Murcia & 1.297 & Recreativo & 1.288 & Espanyol & 1.093 & Osasuna & 1.090 \\
\hline Badajoz & 1.260 & Las Palmas & 1.285 & Las Palmas & 1.278 & Osasuna & 1.093 & Badajoz & 1.025 \\
\hline Logrones & 1.252 & Racing San. & 1.276 & Logrones & 1.265 & & & & \\
\hline Murcia & 1.251 & Univ. LPalmas & 1.261 & Oviedo & 1.255 & & & & \\
\hline Albacete & 1.250 & Badajoz & 1.259 & Badajoz & 1.229 & & & & \\
\hline Toledo & 1.247 & Valladolid & 1.247 & Toledo & 1.219 & & & & \\
\hline Univ. LPalmas & 1.245 & Racing Fer. & 1.235 & Compostela & 1.214 & & & & \\
\hline Racing San. & 1.216 & Córdoba & 1.227 & Ecija & 1.191 & & & & \\
\hline Compostela & 1.210 & Logrones & 1.221 & Albacete & 1.187 & & & & \\
\hline Racing Fer. & 1.199 & Toledo & 1.220 & Valladolid & 1.166 & & & & \\
\hline Córdoba & 1.190 & Albacete & 1.219 & Espanyol & 1.143 & & & & \\
\hline Leganés & 1.190 & Leganés & 1.201 & Córdoba & 1.114 & & & & \\
\hline Hercules & 1.180 & Compostela & 1.189 & Hercules & 1.106 & & & & \\
\hline Oviedo & 1.164 & Oviedo & 1.170 & Eibar & 1.080 & & & & \\
\hline Eibar & 1.160 & Jaen & 1.160 & Ourense & 1.046 & & & & \\
\hline Jaen & 1.150 & Hercules & 1.159 & Racing Fer. & 1.044 & & & & \\
\hline At. Bilbao & 1.130 & Eibar & 1.157 & Sevilla & 1.005 & & & & \\
\hline Ourense & 1.127 & At. Bilbao & 1.150 & Almería & 1.000 & & & & \\
\hline Sevilla & 1.112 & Espanyol & 1.114 & At. Bilbao & 1.000 & & & & \\
\hline Valladolid & 1.105 & Sevilla & 1.111 & Elche & 1.000 & & & & \\
\hline Espanyol & 1.100 & Ourense & 1.109 & Jaen & 1.000 & & & & \\
\hline Osasuna & 1.096 & Osasuna & 1.096 & Osasuna & 1.000 & & & & \\
\hline Elche & 1.080 & Elche & 1.082 & Univ. LP & 1.000 & & & & \\
\hline Almería & 1.070 & Almería & 1.063 & Zaragoza & 1.000 & & & & \\
\hline Mean & 1.452 & Mean & 1.525 & Mean & 1.517 & Mean & 1.524 & Mean & 1.569 \\
\hline
\end{tabular}

Note: (1) and (4): Half-Normal distribution, $\theta$ constant over time but varies across clubs.

(2) and (5): Half-Normal distribution, $\theta_{i t}$ varies over time and across clubs. The table presents the mean for each club over the period.

(3): Fixed effects technique: No distribution required, $\theta_{i}$ constant over time but varies across clubs. 